\title{
SUBRAYADOS O CUANDO MARÍA MORENO LEVANTA LA CABEZA
}

Sobre María Moreno. Subrayados. Leer hasta que la muerte nos separe. Buenos Aires: Mardulce, 2013. 291 pp.

Julieta Viú

UNR

CONICET

Subrayados es una antología que viene a saldar una deuda, a compensar un vacío, ya que se trata de la primera compilación de ensayos que María Moreno, una de las mayores referentes del campo cultural argentino contemporáneo, escribió sobre literatura. Para comprender la importancia de la aparición de este volumen, es necesaria una breve periodización: hasta el 2013, la autora sólo antologó su producción literaria; sin embargo, desde su ingreso al periodismo, en 1980, también escribió reseñas y ensayos críticos. Si trazamos un recorrido por esta producción, debemos referir a los textos que por aquel entonces publicó en la sección "Vogue Libros" de la revista Vogue, escritos que hoy resultan prácticamente desconocidos, y continuar, por el costado más famoso, con sus colaboraciones para Babel. Revista de libros, Debate y Página/12, entre otros prestigiosos medios culturales. Por supuesto, no podemos olvidar que parte de su producción crítica la conforma también una innumerable cantidad de prólogos a obras de escritores jóvenes y no tan jóvenes que Moreno escribió en su tarea de gestora cultural. La mayoría de estos materiales críticos se encuentran dispersos y, en muchos casos, olvidados. Aquí radica entonces el valor de Subrayados que 
compila parte de lo que esta escritora publicó en la revista Debate y el diario Página/12. De modo que el volumen recupera y pone a disposición una gran cantidad de reflexiones literarias de difícil acceso.

El título del libro (Subrayados), que deriva del título de la columna que tuvo en la revista Debate ("El subrayado es mío"), explicita el eje organizador de los textos: Moreno escribe sobre lecturas que han despertado, en ella, reflexiones diversas, ese momento que Barthes cifra lúcidamente en el gesto físico de levantar la cabeza: "¿Nunca os ha sucedido, leyendo un libro, que os habéis ido parando continuamente a lo largo de la lectura, y no por desinterés, sino al contrario, a causa de una gran afluencia de ideas, de excitaciones, de asociaciones? En una palabra, ¿no os ha pasado nunca eso de leer levantando la cabeza?" (Barthes, 2003, p. 31). Algo de ello sucede cuando nos acercamos a los escritos de Subrayados porque imaginamos a Moreno levantando la cabeza en su experiencia de lectura de las escenas citadas y, a su vez, porque nosotros mismos como lectores del libro levantamos la cabeza en más de una situación para retener las ideas que nos vienen a la mente. Quien haya leído a la autora seguramente habrá experimentado algo similar, ya que los ingeniosos e inesperados giros, propios de su estilo literario, al sorprender al lector, lo obligan, si no a parar, al menos a aminorar la velocidad de lectura.

Subrayados está constituido a partir de un sinnúmero de escenas literarias que Moreno recupera de su propia experiencia como lectora, escenas que evidentemente han quedado, en ella, grabadas a fuego. El subrayado que abre el libro refiere a un pasaje de Una excursión a los indios ranqueles de Lucio V. Mansilla, donde a partir de una escena de archivo es posible recuperar la figura de este escritor como un lectorintérprete que asume su papel de oficial de contrainteligencia y, al mismo tiempo, es capaz de aprender de la experiencia. Este 
comienzo resulta significativo porque Mansilla es uno de los referentes literarios de Moreno, un escritor por el que siente una gran devoción. Este texto abre la sección del libro titulada "La nacional", cuyo eje gira en torno a la patria o a los discursos que la literatura ha construido sobre ella: proliferan allí una gran cantidad de autores y obras que se van conectando o, mejor dicho, que Moreno va articulando entre sí: al reflexionar sobre los sentidos que adquiere el agua en la literatura, pasamos por Alfonsina Storni y Fray Mocho hasta llegar a Haroldo Conti y Horacio Quiroga y a las fotografías de Helen Zout. La relación entre literatura y patria provoca, en la escritora, el recuerdo de las ficciones corporales de la generación del ochenta en "Cuerpo argentino" y, al mismo tiempo, de la novela La intemperie de Gabriela Massuh en "Dos eran país". En la misma sección, encontramos también un tributo a la lectura que David Viñas realizó de la literatura argentina y dos escritos sobre el tango, "Y todo asî" y "Gardel". La inclusión de estos últimos textos obedecen, según afirma la autora, a que su primer subrayado fue de oído: cuenta, en más de un prólogo, que su contacto con la literatura tuvo lugar escuchando letras de tango y que fueron ellas las que la llevaron a la poesía modernista. Esta sección cierra con el texto "Leer hasta que la muerte nos separe", subtítulo del libro, en el que Moreno, al indagar su propia historia de la lectura, encuentra, en su infancia, lecturas lúdicas, hechas "de atrás para adelante y del lado de adentro" (110); también lecturas fingidas (cuando su madre la obligaba a leer); mientras que, de grande y para entretenerse, se entrega a lecturas literales: "me gusta leer en los carteles 'Hospital privado de ojos' o ' Silencio hospital', el sentido de un hospital al que se le han sacado los ojos y otro al que se le pide silencio" (110). La lectura, desde la perspectiva de Moreno, adquiere múltiples formas: además de las citadas, también refiere a escenas 
conmovedoras, propias del momento de aprendizaje, y a escenas de lectura de escritores.

"Paso de las lenguas", el segundo apartado del libro, reúne ensayos que presentan la particularidad de ingresar a las obras por un costado en tanto no abordan el texto sino las zonas liminares de éste como son, por ejemplo, las dedicatorias ("El dedicado como autor"), las anécdotas literarias ("La aneda") o el encargo de un texto ("Literatura y constipación"), entre otros. Estas zonas en las que Moreno pone el foco parecen, ante un primer acercamiento, marginales; sin embargo, es interesante observar cómo vuelve productivos esos umbrales al interpretar, por ejemplo, las anécdotas como espacios fundamentales en la invención de un autor o, en relación con las dedicatorias, al retomar la propuesta del psicoanalista Jorge Jinkis de que "como lectores cambiaría nuestra apreciación de la obra si la conociéramos, no ya por el nombre del autor, sino por aquel al que está dirigida" (179). Ante ello, Moreno afirma: "de acuerdo a la teoría de Jinkis me autorizo a decir que las obras completas de Colette y la trilogía Puerca Tierra de John Berger se deberían llamar María Moreno (que ese no sea mi nombre es otra cuestión) ya que, no habiéndome sido dedicados, los lé́, aunque sin mí, como totalmente dirigidos a mí” (180). Al igual que en el primer apartado, en este también aparecen referencias literarias variadas que van de Virginia Woolf a Mario Bellatin y de Charles Baudelaire a Sigmund Freud, por nombrar algunos.

Los textos reunidos tanto en la primera como en la segunda sección son escritos generalmente breves donde prevalece la asociación libre que conduce al lector por distintas escenas, chismes y anécdotas literarias. Al desentenderse del rígido discurso académico, se logra allí desacralizar obras y autores canónicos y, de esta manera, presentar nuevas lecturas que no pretenden ser más que eso: lecturas. Distinto es el caso de los 
escritos agrupados en la tercera y última sección, titulada "Tres ensayos patrióticos", que tienen el objetivo de aproximarse a una lectura de corte teórico a partir de generar un diálogo intenso con los textos. En este sentido, ya no se trata de asociaciones y derivaciones azarosas sino de complejos vínculos y conexiones que provocan ingeniosas hipótesis. Como sucede en el penúltimo subrayado -en el que nos detenemos por la sencilla razón de que nos hizo levantar la cabeza-, dedicado a la escritura de Rodolfo Walsh y Manuel Puig, donde Moreno observa que los registros que ambos escritores construyen están íntimamente ligados a la capacidad de poner al servicio de la literatura un avance técnico como fue el grabador. Este ensayo, que podemos leer como un homenaje por la admiración que deja traslucir, presenta sutiles reflexiones sobre el quehacer periodístico, específicamente, sobre el tipo de registro que ambos fueron capaces de lograr en una época marcada por el cuestionamiento a la noción de autor y la lucha contra la prepotencia del referente. Como explicita la autora, "Walsh y Puig [comenta en relación con el grabador] lo usaron, menos como garantía de una fidelidad al testigo $\mathrm{o}$ al referente que como un robot ficcionalizador recargable y de infinitas posibilidades" (272). Allí, observa distintos modos de apropiación de la voz ajena: la originalidad de Walsh radica en trabajar los testimonios con herramientas propias de la ficción; mientras que en Puig la apuesta está en la 'traducción' de esa voz a partir de la primera persona. En relación con este último y para señalar una diferencia con Walsh, la escritora nos recuerda que las mayores intervenciones de Puig corresponden a la etapa de la grabación. "Puig con Walsh" se convierte así en una interesante reflexión sobre el uso literario de la voz donde Moreno vuelve sobre un tema recurrente: la entrevista. Este texto cobra un valor particular por el diálogo que entabla con el prólogo "Entre nos (apuntes para una teoría de la entrevista)" a Vida de vivos 
(2005), donde Moreno teoriza también sobre este género al que le dedicó buena parte de su vida.

Moreno ofrece recorridos, trayectos e itinerarios de lectura que nos permiten, en algún sentido, acercarnos a su biblioteca, a ese archivo literario que construye a partir de inclusiones y exclusiones, de recuerdos y de olvidos. El subrayado se presenta como una experiencia subjetiva capaz de despertar la reflexión crítica y, al mismo tiempo, el goce que toda buena lectura es capaz de generar. Señalamos, como uno de los aspectos más interesantes de Subrayados, la capacidad que Moreno tiene de leer obras infinitamente leídas y encontrar allí nuevos sentidos.

\section{Referencia Bibliográfica}

Barthes, R. (2003). El susurro del lenguaje. Madrid: Editora Nacional. 